\title{
Solid State Transformer: An Overview of Circuit Configurations and Applications
}

\author{
Nasiru B. Kadandani ${ }^{1,2}$, Mohamed Dahidah ${ }^{1}$, Salaheddine Ethni ${ }^{1}$ and James Yu ${ }^{3}$ \\ ${ }^{1}$ School of Engineering, Newcastle University, NE1 7RU, Newcastle, United Kingdom. N.B.Kadandani2@newcastle.ac.uk \\ ${ }^{2}$ Department of Electrical Engineering, Beyero University, PMB 3011, Kano, Nigeria. nbkadandani.ele@buk.edu.ng \\ ${ }^{3}$ Scottish Power Energy Networks, Blantyre, United Kingdom. James.Yu@ scottishpower.com
}

Keywords: SST, LFT, Single-stage SST, Two-stage SST, Three-stage SST.

\begin{abstract}
This paper first outlined the motivation behind solid state transformer (SST) against conventional line frequency transformer (LFT) as well as its functional futures and benefits and secondly explore all the possible configurations of SST in terms of circuit configurations, advantages, disadvantages and their potential areas of applications. Four circuit configurations considered in this paper include; single stage SST, two stage SST with low voltage DC link (LVDC), two stage SST with high voltage DC link (HVDC) and three stage SST. Our findings reveals that apart from providing voltage regulation, SST can provide other additional ancillary services to the grid to enable it cope with transients. These services (such as power quality improvement, fault isolation, instantaneous voltage regulation, active and reactive power compensation) are not offered by LFT, as such SST is considered as the potential transformer in smart grid applications, renewable energy integration, modern traction systems and other applications where space and volume are critical.
\end{abstract}

\section{Introduction}

The ever increasing demand of energy necessitates the need for harnessing energy from all possible sources including renewable ones. However, large penetration of renewable energy like wind and solar into distribution grid is changing the behaviour of the later from being passive and static to the form of active and dynamic. This is due to the powerinjection variability associated with such energy sources on one hand and their distributed presence in the distribution grid on the other hand [1]. The consequence of this is that the grid is now working with power transients resulting in difficult voltage control, improper breaker operation and islanding detection. This provides a challenging motivation of transforming the grid to smart one to cater for these contingencies on one hand and to develop another smart technique for interfacing the renewable energy sources with the power grid.

Conventional line frequency transformers (LFT) have for long time been used in electrical power system network to achieve voltage transformation. LFT enable high-efficiency and long-distance power transmission by raising the voltage to higher level in the generation side and stepping it down to a lower level for industrial, commercial, and residential uses. The development trends of LFTs are mainly focused on new magnetic materials, insulation materials, manufacturing processes, and other economic factors. Although LFT has high efficiency and low cost, but they suffers the disadvantages of heavy weight, low power density, poor voltage regulation and harmonic isolation capability. One other serious and yet challenging issue about LFT is in grid integration of renewable energy, where additional circuitry such as Static Synchronous Compensator (STATCOM), a member of Flexible Alternating Current Transmission System (FACTS) is required for interfacing the renewable energy source with the power grid.

A promising solution for the aforesaid drawbacks of LFT is SST. This device can apart from providing voltage transformation also provides flexible methods for interfacing renewable energy sources with power grid with improved methods of controlling the routing of electricity and power flow, as well as safe operation of the grid. A typical SST consists of an AC/DC rectifier, a DC/DC converter with highfrequency transformer and a DC/AC inverter. SST being a power electronics based transformer is capable of providing greater flexibility in low and medium voltage grids than the conventional LFT. Other additional features and functions of SST include [2]:

- $\quad$ Reduced size and weight

- Instantaneous voltage regulation

- Fault isolation

- Power factor correction

- Control of active and reactive power flow

- Fault current management on both low-voltage and high voltage sides

- Active power filtering of harmonic content

- The output can have a different frequency and number of phases than the input

- Possibility of a DC input or output

- Voltage dip and sag ride though capability

- Smart grid integration

Researchers in [3-10] have investigated the potential of SST in distribution and traction systems. A review of literature 
available on SST and other related FACTS devices revealed the need for new technologies in our electrical grid networks. Similarly, the increase of renewable energy penetration (like wind) and other distribution sources into our grids, along with the liberation of the electricity market have caused the grid layout to become more complex. In order to quickly and efficiently manage the changing sources and loads, the SST can be used to dynamically adjust the energy distribution in the grid. SST combines power electronics with a high frequency transformer (HFT) that is reduced in for providing voltage transformation and other functionalities. Another possible advantage of this technology is that it allows the output voltage to be better regulated even when there are fluctuations from the input. In addition, SST allows add-on intelligence to enhance power quality compatibility between source and load. Furthermore, the device is insensitive to harmonics, has zero regulation, prevents load disruptions and faults from affecting the primary system, can supply loads with DC offsets, and does not utilize a liquid dielectric. In fact, SST can support both AC and DC connected energy cells, a combination of distributed energy resources (DER), distributed energy storage (DES) and loads. It can also achieve real-time power flow regulation via the energy Cell, therefore forming the foundation of its capability to become a real-time energy router [11].

\section{Motivation for SST}

The following are some of the major reasons motivating the use of SST against LFT:

- $\quad$ SST is universal, as such, power can be utilized in both AC and DC forms. It also integrates features of different components into a single unit.

- SST can provide power quality improvement, as such, reactive power compensation and system harmonic filtering can be guaranteed.

- SST can guarantee fault isolation, - power supply disturbances cannot propagate to the load side.

- SST provides instantaneous voltage regulation, without the need for a tap changer.

- SST can provide voltage and frequency control thereby reducing the system losses.

- $\quad$ SST integrates energy storage. This feature makes it capable of providing backup and reducing the duration of outages.

- $\quad$ SST can provide power in DC form. The LVDC bus in SST also allows interfacing local DC systems

- $\quad$ SST provides complete decoupling of reactive power flow from either side, hence, no propagation of disturbance.

\section{Features and Benefits of SST}

1. Integration of Distributed Energy Resources

As reported in [12] SST can be used for the integration of distributed energy resources such as wind and solar optimally and with power quality improvement.

\section{Additional Interconnection Points}

SST have several ports such as AC and DC power ports, single and three phase system, 50 and $60 \mathrm{~Hz}$ frequency [13]

\section{Reliability Improvement}

SST can guarantee the reliability of power system by integrating renewable energy sources from DG [14].

\section{Active and Reactive Power Control}

SST performs the function of power control by controlling the power factor of the system [15-18].

\section{Control of Voltage Fluctuations}

SST is capable of mitigating voltage variations in form of voltage sag (voltage dip), voltage swell (voltage rise), voltage transient, voltage flicker and voltage imbalance $[19,20]$.

\section{Mitigation of Current Harmonics}

SST is capable of mitigating harmonics such as those demanded by non-linear loads. It is also capable of controlling current overshoot that may arise as a result of connecting or disconnecting loads [21, 22].

\section{Reduction in Footprint}

Conventional LFT suffers the disadvantage of having large amount of copper and iron, requiring space and incurring high costs for transportation, volume and weight. The use of HFT in SST makes it much more reduced in size. This brings economic advantages to both manufactures and customers.

\section{Eliminating Fire Hazardous and the use of Oil}

A well designed SST with portable HFT may not need transformer oil. It is also safe of fire hazards.

\section{Flexibility and Intelligence}

SST can be regarded as smart transformer. As such, it is an active interphase between low voltage and high voltage side, such that disturbance on one side cannot propagate to the other side. It is also capable of detecting and addressing power quality disturbance.

\section{Circuit Configurations of SST}

SST transforms the 50 or $60 \mathrm{~Hz}$ AC voltage to a high frequency one which is further stepped up/down by HFT with appreciable decrease in volume and weight, and finally, shaped back into the desired $50 / 60 \mathrm{~Hz}$ voltage to feed the load as shown in figure 1 .

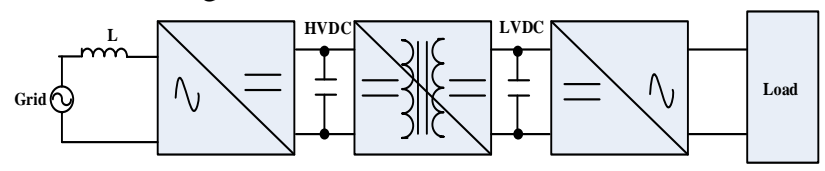

Figure 1: SST Configuration

SST can be realized in one of four configurations, namely:

- $\quad$ Type A: Single-stage SST with no DC link

- Type-B: Two-stage SST with a DC link on the secondary side 
- Type C:Two-stage SST with a DC link on the primary side

- $\quad$ Type D: Three-stage SST with a DC link on both primary and secondary sides

\section{A. Single Stage SST}

\section{$\underline{\text { Description }}$}

Single stage SST typically uses an AC-AC full bridge converter which converts the low frequency $\mathrm{AC}$ input to a high-frequency one which is then stepped down using HFT. The output of the HFT is further converted to power frequency using another converter. In this topology, the SST is essentially an isolated AC/AC converter with a mediumfrequency link (figure 2).

\section{Circuit Configuration}

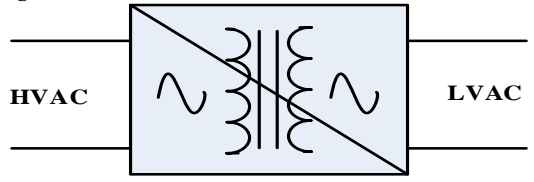

Figure 2: Block Diagram of Single Stage SST

Different converter topologies can be used to realise the block diagram shown in figure 2. A typical configuration of single stage SST involving an AC-AC full-bridge converter is shown in figure 3.

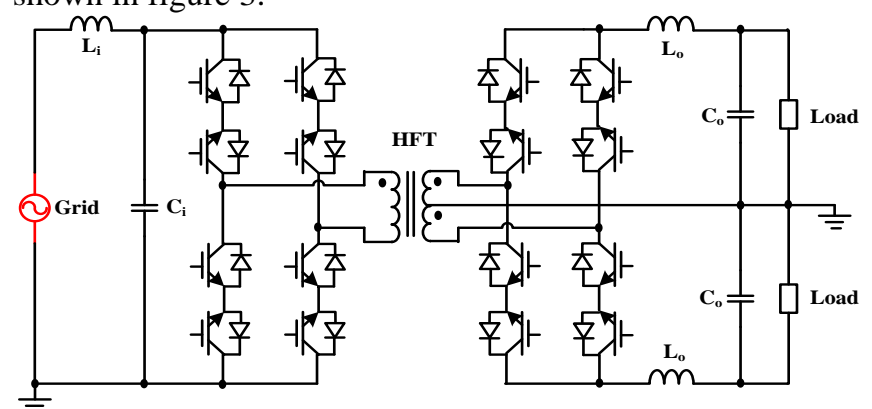

Figure 3: Circuit Configuration of Single Stage SST based on Full-bridge AC-AC Converter

\section{$\underline{\text { Advantages }}$}

- Simple configuration with minimum component count

- Low cost and light weight

- Simple construction

- Very simple modularity implementation

- It uses a minimum amount of copper

- Least losses due to the presence of fewer number of semiconductor switches

\section{$\underline{\text { Disadvantages }}$}

- Lack of DC link makes them unsuitable for applications where reactive power compensation is required.

- Disturbances on one side may affect the other side

- No input current regulation

- The absence of the DC link makes power factor correction difficult

- $\quad$ No LVDC for connection to DES and DER
- No DC-DC conversion stage which is responsible for the galvanic isolation and voltage adaptation.

- Large ripple currents, hence, large size filters are required

- Difficult control method because of the absence of DC link

- No input and output current limiting capability

- Cannot provide HVDC and LVDC under and overvoltage protection

- Frequency is fixed, hence it cannot provide power factor correction

\section{Other Technical Constrains}

- Complex control algorithm

- Heat (thermal) management

- Each switch must be able to block full primary voltage and also be capable of conducting full secondary current.

- Commutation of leakage energy which results in power loss, reduction in switching frequency, loss of output voltage, and additional common-mode voltage switching

- Redundancy, - only for series-connection of power semiconductors

\section{Areas of Applications}

- High-power-density motor drives

- Modern traction system

\section{B. Two Stage SST with LVDC Link}

\section{Description}

As shown in figure 4 , in this configuration, an isolated ACDC conversion stage provides the low DC voltage followed by a DC-AC conversion stage to provide the low voltage AC.

\section{Circuit Configuration}

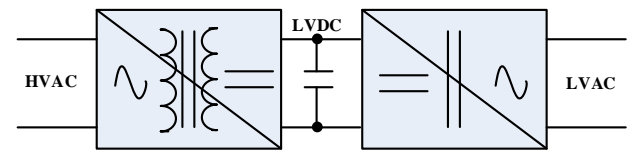

Figure 4: Block Diagram of Two Stage SST with LVDC

A typical circuit configuration of two stage SST with LVDC based on an AC-DC dual active bridge (DAB) converter is shown in figure 5 . The AC-DC transformation is realised by the $\mathrm{DAB}$ converter while a double phase inverter transforms the $\mathrm{DC}$ voltage to $\mathrm{AC}$.

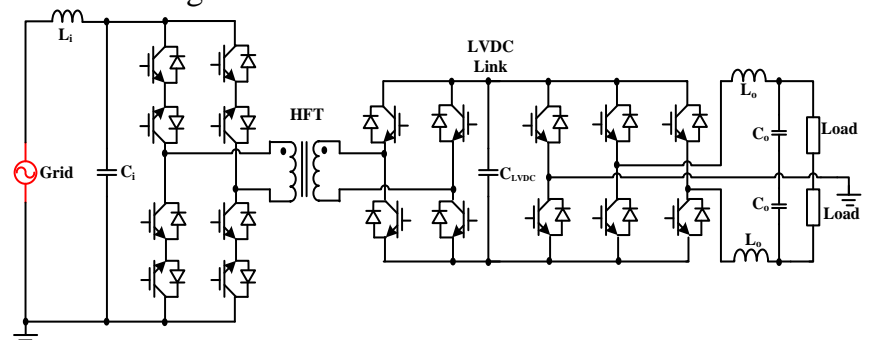

Figure 5: Circuit Configuration of Two Stage SST based on DAB AC-AC Converter 
Advantages

- It enables reactive power support to the grid

- Its LVDC support DES and DER

- It supports DES management

- Good output voltage and input current regulation

- Good input voltage sag ride through capability

- Input and output current limiting capability

- $\quad$ Provides LVDC under and overvoltage protection

- It has independent frequency and independent power factor

- It has a very simple modularity implementation

- It enables isolation of load and grid side transients

- Suitable for integration of DC sources, storage devices and loads.

Disadvantages

- The LVDC link always have larger ripple current due to the absence of the HVDC

- High sensitivity of average active power flow to leakage inductance variation

- It cannot provide HVDC link regulation

- Cannot provide HVDC under and overvoltage protection.

- Not suitable for high voltage operation since ZVS is hard to be guaranteed.

- Mature multilevel topologies cannot be easily applied in the high voltage side.

- It has high switching losses which can lead to lower efficiency and difficult thermal management.

\section{Other Technical Constrains}

- Efficiency

- High switching losses

- Reliability

\section{Area of Applications}

- Integration of renewable energy sources on the low DC voltage (potentially residential)

- Power-quality related features such as power-factorcorrection, reactive-power compensation and active filtering

- DC Microgrid applications

- Smart Grid such as photovoltaic panels, storage devices, fuel cell and dc-type loads

- In interfacing DC sources, loads and storage units

\section{Two Stage SST with HVDC Link}

\section{Description}

This configuration as shown in figure 6, is a two-stage conversion in which the galvanic isolation and voltage stepdown are done by the DC-AC stage, therefore LVDC link is not available.

\section{Circuit Configuration}

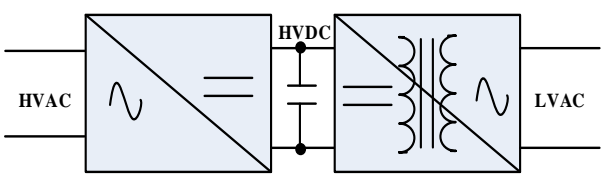

Figure 6: Block Diagram of Two Stage SST with HVDC Link

Advantages

- It enables reactive power support to the grid

- It supports DES management

- Good output voltage and input current regulation

- Good input voltage sag ride through capability

- Input and output current limiting capability

- It has independent frequency and independent power factor

- A two-stage SST with HVDC link is suitable for high voltage operation.

\section{Disadvantages}

- High ripple current and high sensitivity of active power flow on leakage inductance.

- The absence of LVDC bus makes integration of renewable resources on the low voltage (potentially residential) side unfeasible.

Other Technical Constrains

- Efficiency

- Reliability

Applications

- DC Distribution system

- High voltage direct current (HVDC) applications

- Ideal for connecting the remote offshore platforms and wind farms to the onshore grid

- DC Microgrid applications

- Modern unified power quality conditioner (UPQC)

- Voltage Transformation with decreased volume and space

\section{Three Stage SST}

\section{Description}

Figure 7 shows a three stage SST. It involves a three-stage conversion with high frequency isolation in the DC-DC stage, as such, both LVDC and HVDC can be obtained. This configuration typically includes a high-voltage AC to DC power conversion stage to generate a high voltage DC bus, a high-frequency DC/DC converter stage to produce a regulated low voltage $\mathrm{DC}$ bus, and a DC/AC stage to produce a regulated low voltage $\mathrm{AC}$ bus.

\section{Circuit Configuration}

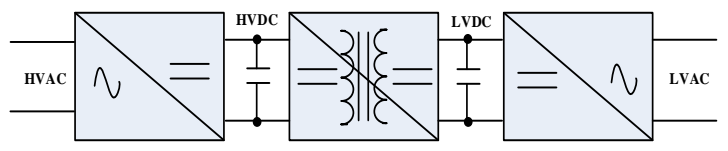

Figure 7: Block Diagram of Three Stage SST 
Several converter topologies can be used to realise a three stage SST. A typical circuit configuration of this topology comprising a full-bridge converter, a DAB converter and a double phase inverter is shown in figure 8. The AC-DC transformation is provided by the full-bridge converter. The DAB converter does the DC-DC transformation while the double phase inverter performs the DC-AC transformation.

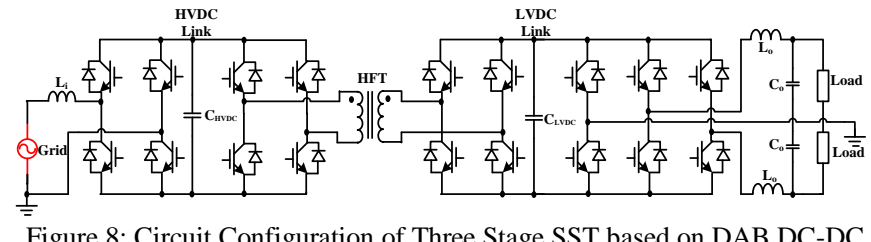
Converter

The three-stage SST is the most feasible configuration that allows enjoying all the benefits associated with SST. In fact, the configuration has been considered for high power applications by designing each of the three conversion stages of the configuration using multilevel converter topologies [23-25]. A typical circuit configuration of the three stage SST using multilevel converter topology is shown in figure 9 .

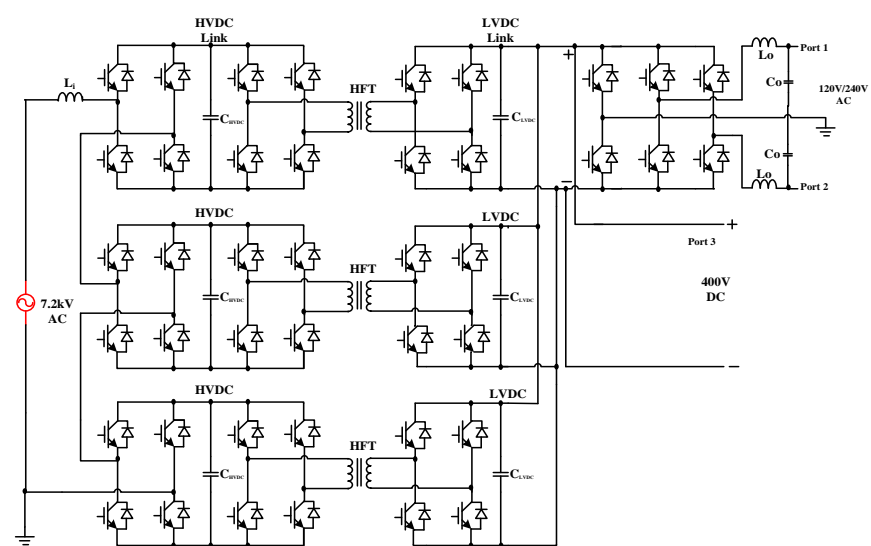

Figure 9: Cascaded Modular Three Stage SST

A successful design and implementation of generation-I SST single phase 20kVA was reported in [26]. The design which employed the configuration of figure 9 was based on $6.5 \mathrm{kV}$ $\mathrm{Si}$-IGBT and was meant for interfacing $12 \mathrm{kV}$ distribution system. Another design and hardware implementation of the same configuration was also reported in [27]. Researchers in [28-30] proposed a control strategy for balancing the voltage and power in such multilevel SST configuration. The method is based on single phase $d-q$ vector control in regulating the rectifier capacitor voltages and the real power through the DAB parallel modules. Similar control strategy was also reported in for cascaded modular SST and H-bridge converter based SST.

\section{$\underline{\text { Advantages }}$}

- High flexibility

- Superior controllability

- The DC links enable independent reactive power control

- $\quad$ Its LVDC support DES and DER management
- Good output voltage and input current regulation

- Good input voltage sag ride through capability

- Input and output current limiting capability

- It has a very simple modularity implementation

- Good LVDC and HVDC link regulation

- It enables HVDC and LVDC under and overvoltage protection

- The DC-DC conversion stage enables galvanic isolation and voltage adaptation.

- It provides reactive power compensation

- Voltage sag compensation

- It supports renewable energy resources and energy storage integration.

- It can integrate distribution system, residential AC system and envisioned DC system.

\section{Disadvantages}

- The large number of switching devices may lead to higher losses

- High switching losses which can lead to lower efficiency and difficult thermal management.

- Impedance mismatching

- High number of converter levels leads to higher cost

- Low cell switching frequency

- High conduction Losses

Other Technical Constrains

- Efficiency

- Robustness

- Volume and weight

- Extremely high dv/dt in the high voltage

- Coupling effect between the voltage balance controller and the original system controller.

Areas of Applications

- Grid integration of renewable energy sources (such as wind, solar and tidal) with distribution system.

- Energy router for universal and flexible power management for future electricity network

- Power quality control (reactive power compensation and harmonic filtering).

- Fault isolation and limitation

- Powering traction and other locomotive system.

- Powering remotely operated vehicle

- Large DC powered ships

- In data centres to reduce losses and footprint as well as improving reliability and power quality.

- DC fast charger application

- Voltage transformation and isolation

- DC collection grids for offshore wind parks

\section{Conclusion}

In this paper, an overview of solid state transformer is detailed. The paper first outlined the motivation behind SST against LFT, as well as features and benefits of SST. The 
paper also outlined different circuit configurations/topologies of SST, their advantages, disadvantages, as well as their potential areas of application. In this regard, it was established that SST has overtaken LFT in terms of reduced size, weight, compactness, cable solution, multiport capability, intelligence and environmental friendliness as such it can be employed for multi-task objective. Furthermore, the summary of the overview of the four configurations will simplify a long term decision making for system vendors, utility operators and other stake holders in deciding suitable SST configuration for a particular task.

\section{Acknowledgements}

The authors would like to thank Scottish Power Energy Networks for its partial financial support towards this work through the Network Innovation Allowance Project No. RES/0560/7466/002.

\section{REFERENCES}

[1] L.F. Ferreira, G.D. Carne, G. Buticchi, and M. Liserre, "The Smart Transformer - A Solid-State Transformer tailored to Provide Ancillary Services to the Distribution Grid," IEEE Power Electronics Magazine, pp. 56-67 2017.

[2] X. She and A. Q. Huang, "Solid State Transformer in the Future Electrical System," Proceedings of IEEE Power and Energy General Meeting (PES), 2013.

[3] X. She, A. Q. Huang, and R. Burgos, "Review of Solid-State Transformer Technologies and Their Application in Power Distribution Systems," IEEE Journal of Emerging and Selected Topics in Power Electronics, vol. 1, pp. 186-198, 2013.

[4] J. W. Kolar and G. Ortiz, "Solid-State-Transformers: Key Components of Future Traction and Smart Grid Systems " Proceedings of the International Power Electronics Conference ECCE Asia (IPEC), 2014.

[5] D. Grider, M. Das, A. Agarwal, J. Palmour, S. Leslie, J. Ostop, et al., "10kV/120A SiC DMOSFET Half-Bridge Power Modules for 1MVA Solid State Power Substation," Proceedings of IEEE Electric Ship Technology Symposium, pp. 131-134, 2011.

[6] A. M. J. S. Lai, A. Mansoor, and F. Goodman, "Multilevel Intelligent Universal Transformer for Medium Voltage Application," Proceedings of IEEE Industrial Appliances Conference, pp. 1893-1899, 2005.

[7] D. Dujic, C. Zhao, A. Mester, J. K. Steinke, M. Weiss, S. L. Schmid, et al., "Power Electronic Traction Transformer: Low Voltage Prototype," IEEE Transactions on Power Electronics, vol. 28, pp. 5522-5534, 2013.

[8] S. Bifaretti, P. Zanchetta, A. Watson, L. Tarisciotti, and J. C. Clare, "Advanced Power Electronic Conversion and Control System for Universal and Flexible Power Management," IEEE Transactions on Smart Grid, vol. 2, pp. 231-243, 2011.

[9] T. F. Zhao, L. Y. Yang, J. Wang, and A. Q. Huang, "270 kVA Solid State Transformer Based on $10 \mathrm{kV}$ SiC Power Devices," Proceedings of IEEE Electric Ship Technology Symposium, pp. 145-149, 2007.

[10] E. R. Ronan, S. D. Sudhoff, S. F. Glover, and D. L. Galloway, "A Power Electronic-Based Distribution Transformer," IEEE Transactions on Power Delivery, vol. 17, pp. 537-543, 2002.

[11] S. Hambridge, A.Q. Huang, and R.Yu, "Solid State Transformer (SST) as an Energy Router: Economic Dispatch Based Energy Routing Strategy," Proceedings of IEEE Energy Conversion Congress and Exposition (ECCE), pp. 2355-2360, 2015.

[12] L. Heinemann and G. Mauthge, "The Universal Power Electronics Based Distribution transformer, An Unified Approach," Proceedings of Power Electronics Specialist Conference (PESC), vol. 2, pp. 504-509, 2001.

[13] M. Sabahi, A. Y. Goharrizi, S. H. Hosseini, M. B. B. Sharifian, and G. B. Gharehpetian, "Flexible Power Electronic
Transformer," IEEE Transaction on Power Electronics, vol. 25, pp. 2159-2169, 2010.

[14] S. H. Hosseini, M. B. B. Sharifian, M. Sabahi, Z. Hooshi, and G. B. Gharehpetian, "A Tri-directional Power Electronic Transformer for Photovoltaic Based Distributed Generation Application," Proceedings of Power and Energy Society general Meeting (PES), pp. 1-5, 2009.

[15] H. Iman-Eini, S. Farhangi, J. Schanen, and J. Aime, "Design of Power Electronic Transformer Based on Cascaded H-Brdige Multilevel Converter," Proceedings of IEEE International Symposium on Industrial lectronics, pp. 877-882, 2007.

[16] M. R. Banaei and E. Salary, "Power Quality Improvement Based on Novel Power Electronic Transformer," Procedings of Power Electronics, Drive Systems and Technologies Conference (PEDSTC), pp. 286-291, 2011.

[17] H. Iman-Eini, J.Schanen, S. Farhangi, J. Barbaroux, and J. Keradec, "A Power Electronic Based Transformer for Feeding Sensitive Loads," Proceedings of Power Electronics Specialist Conference (PESC), pp. 2459-2555, 2008.

[18] J. Ai-juan, L. Hang-tian, and L. Shao-long, "A New Matrix Type Three-Phase Four-Wire Power Electronic Transformer," Proceedings of Power Electronics Specialist Conference (PESC), pp. 1-6, 2006

[19] D. Wang, C. Mao, and J. Lu, "Coordinated Control of EPT and Generator Excitation System for Multidouble-Circuit Transmission-Line System," IEEE Transaction on Power Delivery, pp. 371-379, 2008.

[20] J. Lai, A. Maitra, and F. Goodman, "Performance of a Distribution Intelligent Universal Transformer Under Source and Load Disturbances," Proceedings of Industry Application Conference, pp. 719-725, 2006.

[21] H. Qin and J. W. Kimball, "A Comparative Efficiency Study of Silicon-based Solid State Transformers," Proceedings of IEEE Energy Conversion Congress and Exposition (ECCE), pp. 14581463, 2010.

[22] M. Saghaleini, A. Hekmati, and S. Farhangi, "An Advanced Distributed Power Supply for Power Electronic Transformers," Proceedings of Industrial Electronics Society Conference (IECON), pp. 2038-2043, 2007.

[23] S. Falcones, X. Mao, and R. Ayyanar, "Topology Comparison for Solid State Transformer Implementation," Proceedings of IEEE Power and Energy General Meeting, pp. 1-8, 2010.

[24] C. Ling, B. Ge, D. Bi, and Q. Ma, "An Effective Power Electronic Transformer Applied to Distribution System " Proceedings of International Conference on Electrical Machines and Systems pp. 1-6, 2011.

[25] I. Roasto, E. Romero-CadavaI, J. Martins, and R. Smolenski, "State of the Art of Active Power Electronic Transformers for Smart Grids," Proceedings of Annual Conference on IEEE Industrial Electronics Society pp. 5241-5246, 2012.

[26] S. Bhattacharya, T.Zhao, G. Wang, S. Dutta, S. Baek, Y. Du, et al., "Design and Development of Generation-1 Silicon Based Solid State Transformer," Proceedings of IEEE Applied Power Electronics Conference and Exposition (APEC), pp. 1666-1673, 2010.

[27] G. Wang, S. Baek, J. Elliot, A. Kadevelugu, F. Wang, X. She, et al., "Design and Hardware Implementation of Gen-1 Silicon Based Solid State Transformer," Proceedings of IEEE Applied Power Electronics Conference and Exposition (APEC), pp. 13441349, 2011.

[28] T. Zhao, G. Wang, J. Zeng, S. Dutta, S. Bhattacharya, and A. Q. Huang, "Voltage and Power Balance Control for a Cascaded Multilevel Solid State Transformer," Proceedings of IEEE Applied Power Electronics Congress and Exposition (APEC), pp. 781-767, 2010.

[29] J. Shi, W. Gou, H. Yuan, T. Zhao, and A. Q. Huang, "Research on Voltage and Power Balance Control for Cascaded Modular SolidState Transformer," IEEE Transactions on Power Electronics, vol. 26, pp. 1154-1166, 2011.

[30] T. Zhao, G. Wang, S. Bhattacharya, and A. Q. Huang, "Voltage and Power Balance Control for a Cascaded H-Bridge ConverterBased Solid-State Transformer," IEEE Transactions on Power Electronics, vol. 28, pp. 1523-1532, 2013 